\title{
The Cerebellar Leptomeningeal Enhancement Associated with Cryptococcal Meningitis
}

Azusa Shiromaru, Ryuta Kinno, Naohito Ito and Kenjiro Ono

Key words: cryptococcal meningitis, Cryptococcus neoformans, leptomeningeal enhancement, cerebellitis

(Intern Med 58: 149-150, 2019)

(DOI: 10.2169/internalmedicine.1491-18)

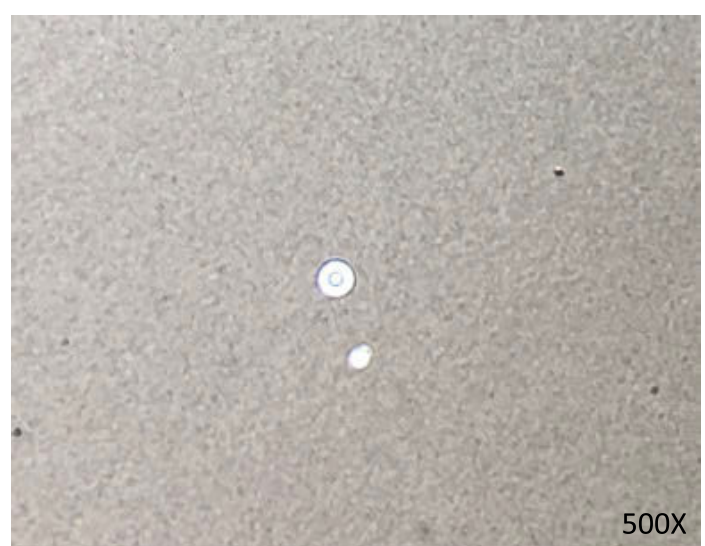

Picture 1.

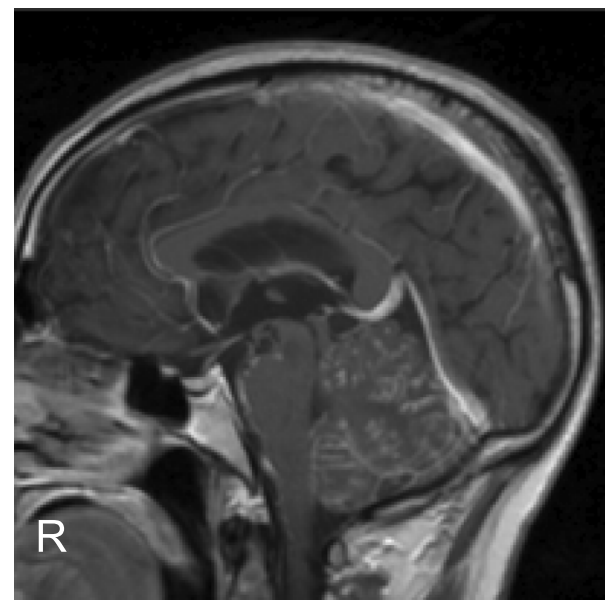

Picture 3.

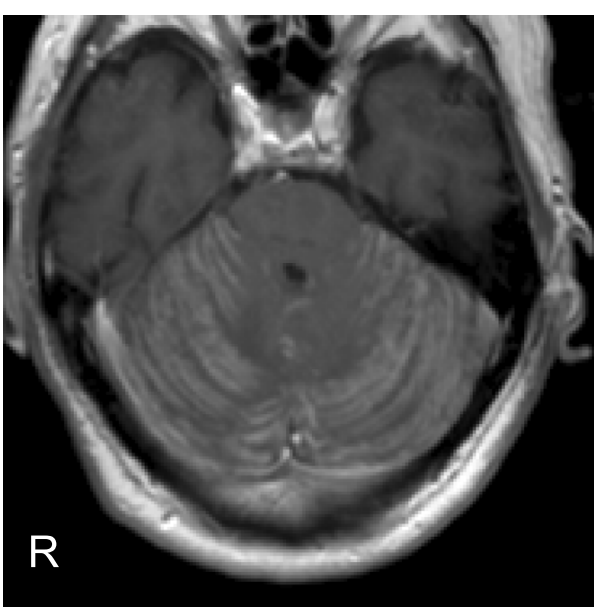

Picture 2.

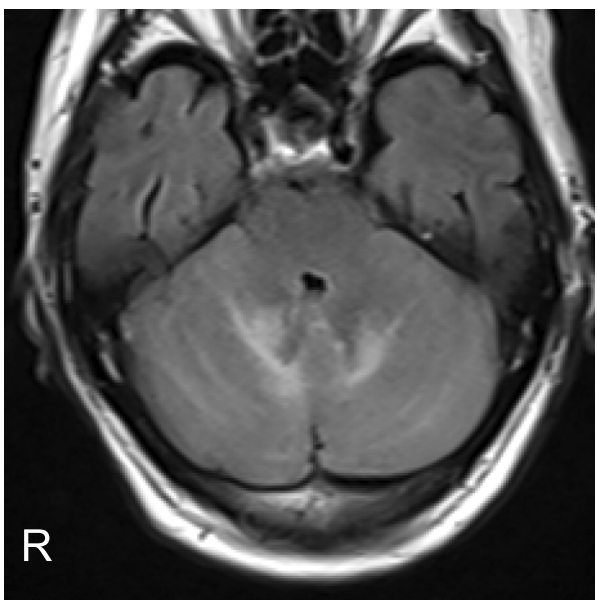

Picture 4.

A 71-year-old male construction worker without human immunodeficiency virus had a headache. He showed meningeal signs and ataxia. His cerebrospinal fluid showed a cell count of $335 / \mu \mathrm{L}(60 \%$ polymorphonuclear leukocytes)

and protein level of $171 \mathrm{mg} / \mathrm{dL}$, with a glucose level of $<10$ $\mathrm{mg} / \mathrm{dL}$. Indian ink staining revealed fungus bodies (Picture 1). Brain magnetic resonance imaging showed enhance- 
ment along the cerebellar folia on contrast T1-weighted imaging (Picture 2, 3). Fluid attenuated inversion recovery imaging showed high-intensity areas at the cerebellar hemispheres and cerebellar swelling (Picture 4). Although leptomeningitis is a common cause of cases of non-AIDSrelated cryptococcal meningitis (1), this is a rare case of cryptococcal meningitis with leptomeningeal enhancement limited to the cerebellum and no apparent cryptococcoma $(2,3)$. Cryptococcus meningitis should be considered in patients with a high risk of inhaling cryptococcus antigen, even when the lesion is limited to the cerebellum and the patient has no pathological antecedents.

The authors state that they have no Conflict of Interest (COI).

\section{References}

1. Chen S, Chen X, Zhang Z, Quan L, Kuang S, Luo X. MRI findings of cerebral cryptococcosis in immuncompetent patients. J Med Imaging Radiat Oncol 55: 52-57, 2011.

2. Lasso FA, Zamora Bastidas TO, Potosí García JA, Díaz Idrobo B. Cryptococcal cerebellitis in no-VIH patient. Colomb Med (Cali) 48: 94-97, 2017.

3. Lane H, Browne L, Delanty N, Neill SO, Thornton J, Brett FM. July 2004: 40-year-old man with headaches and dyspnea. Brain Pathol 15: 89-90, 95, 2005.

The Internal Medicine is an Open Access journal distributed under the Creative Commons Attribution-NonCommercial-NoDerivatives 4.0 International License. To view the details of this license, please visit (https://creativecommons.org/licenses/ by-nc-nd/4.0/).

(C) 2019 The Japanese Society of Internal Medicine Intern Med 58: 149-150, 2019 